\title{
Amino acid-assisted synthesis of strontium hydroxyapatite bone cement by a soft solution freezing method
}

\author{
D GOPI $^{\mathrm{a}, \mathrm{c}, *}$, S NITHIYA ${ }^{\mathrm{a}}$, L KAVITHA ${ }^{\mathrm{b}, \mathrm{c}}$ and J M F FERREIRA ${ }^{\mathrm{d}}$ \\ ${ }^{\mathrm{a}}$ Department of Chemistry, ${ }^{\mathrm{b}}$ Department of Physics, ${ }^{\mathrm{c}}$ Centre for Nanoscience and Nanotechnology, Periyar University, \\ Salem 636 011, India \\ ${ }^{\mathrm{d}}$ Department of Ceramics and Glass Engineering, University of Aveiro, CICECO, 3810-193 Aveiro, Portugal
}

MS received 30 October 2011; revised 28 January 2012

\begin{abstract}
Among many cations that can substitute for calcium in the structure of hydroxyapatite, strontium provokes an increasing interest because of its beneficial effect on bone formation and prevention of bone resorption. Strontium-incorporated calcium phosphates show potential in biomedical application, particularly the doped strontium may help in new bone formation. We have synthesized strontium hydroxyapatite powders at $2^{\circ} \mathrm{C}$ by a soft solution freezing method using glycine as the template. The structural and morphological characterizations were carried out on the as obtained powders using Fourier transform infrared spectroscopy, X-ray diffraction analysis and scanning electron microscopy techniques. Strontium was quantitatively incorporated into hydroxyapatite where its substitution for calcium provoked a linear shift of the infrared absorption bands of the hydroxyl and phosphate groups. The strontium substituted bone cement has potential for use in orthopaedic surgeries. The present study shows that the addition of glycine plays an important role in reducing the particle size of strontium hydroxyapatite which could be used for biomedical applications.
\end{abstract}

Keywords. Strontium hydroxyapatite; freezing synthesis; template; biomaterials; bone cement; bioceramics.

\section{Introduction}

Hydroxyapatite (HAp), $\left[\mathrm{Ca}_{10}\left(\mathrm{PO}_{4}\right)_{6}(\mathrm{OH})_{2}\right]$, has been widely studied as an important biocompatible material because of its chemical similarity to the natural calcium phosphate mineral present in a biological hard tissue (Gomez-Vega et al 2000; Bezzi et al 2003; Wang et al 2008). Calcium phosphate cements are broadly used as bone substitutes in orthopaedic applications for their high biocompatibility as well as osteoconductivity (Guo et al 2005). Among the calcium phosphate cements, hydroxyapatite is reported to show high bone bonding ability. Moreover, HAp is the most thermodynamically stable phase in physiological conditions (Sanosh et al 2010). But pure HAp cannot be used in load bearing applications due to its low mechanical strength (Mardziah et al 2009). It has been demonstrated that the properties of HAp can be tailored over a wide range by modifying the composition through ionic substituents (Suchanek et al 2004; Kannan et al 2008). Several studies have been reported on the synthesis of metal ion substituted HAp and have been shown to improve its structural stability and biocompatible properties (Webster et al 2004; Kalita and Bhatt 2007; Xue et al 2006; Capuccini et al 2008). A great number of substitutions, both cationic and anionic are possible since $\mathrm{Ca}^{2+}$ ion sites can be replaced by various divalent cations including $\mathrm{Sr}^{2+}, \mathrm{Ba}^{2+}, \mathrm{Pb}^{2+}, \mathrm{Mg}^{2+}, \mathrm{Zn}^{2+}$ etc. Among these, strontium

\footnotetext{
*Author for correspondence (dhanaraj_gopi@yahoo.com)
}

is believed to play an important role in the treatment of osteoporosis and enhancement of bone remineralization. Moreover, strontium HAp $\left[\mathrm{Sr}_{10}\left(\mathrm{PO}_{4}\right)_{6}(\mathrm{OH})_{2}\right]$ has received enormous attention because of its crystallochemical similarity to calcium hydroxyapatite (Balamurugan et al 2009). Strontium is also believed to play an important role in the enhancement of bone remineralization as it is associated with a reduction of bone resorption, an increase in the formation of new bone fracture (Pan et al 2009). Recently, strontium hydroxyapatite has shown to hold a great potential for coating titanium implants and as filler for bone cements and toothpastes (Lam et al 2010). Strontium hydroxyapatite, a bioactive bone cement, is used in spinal and bone fracture surgery and it is also used in bone replacement, bone fillings, bone adhesives and for treatment of osteoporosis (Ni et al 2006). The synthesis of strontium hydroxyapatite can be accomplished by using various methods of synthesis like sol-gel (Balamurugan et al 2009), solid titrations (Pan et al 2009), wet chemical (Bigi et al 2007) and sol-gel- supercritical fluid drying (SCFD) methods (Yingguang et al 2008). However, drawbacks of these methods include partial reproduction, inhomogeneity of the architecture and high cost. One approach to overcome these drawbacks is the template direct method (Li et al 2008), which promises ultra fine high quality powders and provides no phase transformations due to decomposition.

To the best of our knowledge there are no reports about synthesis of strontium hydroxyapatite bone cement by freezing method. Sr-HAp bioactive bone cement promotes 
osteoblast attachment and mineralization in vitro as well as bone growth and osteointegration in vivo. Local delivery of strontium with HAp in cement has been shown to induce new bone formation and to be effective in reducing fracture risk in osteoporosis. The oral strontium salts have recently been used as a drug associated with treating osteoporosis. Sr-HAp was synthesized with the purpose of being used locally as a filling material for bone cement (Wong et al 2009). We have now synthesized strontium hydroxyapatite that possesses architecture similar to that of natural bones, which is more bioactive when compared to non-substituted hydroxyapatite. The strontium substituted calcium phosphate cement has potential for use in orthopaedic surgeries. The present paper reports about the successful synthesis of strontium hydroxyapatite bone cement that could be widely used in orthopaedic applications to anchor implants to existing bone, reconstruct bone and deliver bioactive agents to the body by using glycine as template and freezing at $2{ }^{\circ} \mathrm{C}$. The main advantage of this soft solution freezing method is its simplicity and low cost.

\section{Experimental}

Strontium nitrate, $\mathrm{Sr}\left(\mathrm{NO}_{3}\right)_{2}$ and diammonium hydrogen phosphate $\left(\left(\mathrm{NH}_{4}\right)_{2} \cdot \mathrm{HPO}_{4}\right)$ were used as the precursors for $\mathrm{Sr}$ and $\mathrm{P}$, respectively. Glycine was used as a template for overall synthesis. All the chemicals were of analytical grade and aqueous solutions were made by dissolving them in deionized water. Firstly, $0.05 \mathrm{M}$ strontium nitrate, $\mathrm{Sr}\left(\mathrm{NO}_{3}\right)_{2}$, was mixed with varied concentrations of glycine, 0.01 to $1 \mathrm{wt} \%$. The mixtures were continuously stirred under magnetic stirring for $1 \mathrm{~h}$. The precursor mixture, $0.03 \mathrm{M}$ of diammonium hydrogen phosphate was added drop wise to the above mixture until a homogenous white suspension was obtained and this was kept under stirring for about $12 \mathrm{~h}$. $\mathrm{pH}$ of the suspension was adjusted to 9 using $\mathrm{NaOH}$. A milky white precipitate was obtained, which was placed in a freezer for $48 \mathrm{~h}$ at $2{ }^{\circ} \mathrm{C}$ and the precipitate was then dried at $70{ }^{\circ} \mathrm{C}$ for $24 \mathrm{~h}$. The obtained precipitate was calcined for $6 \mathrm{~h}$ to remove the template and finally sintered at $600{ }^{\circ} \mathrm{C}$ for $2 \mathrm{~h}$. The flow chart of the experimental procedure is depicted in figure 1 .

To characterize the synthesized strontium substituted hydroxyapatite powders, Fourier transform infrared spectra (FT-IR) were recorded using Nicolet 380 FT-IR spectrophotometer over a range from 4000 to $400 \mathrm{~cm}^{-1}$ with number of scans being 32 and resolution, $4 \mathrm{~cm}^{-1}$. For this, small amounts of $\mathrm{Sr}-\mathrm{HAp}$ powders were blended with $\mathrm{KBr}$ and then pressed into discs for measurement. X-ray diffractions (XRD) for the synthesized powders were obtained by Bruker D-8 Advanced-Germany spectrometer. The morphology of the synthesized powders was obtained through scanning electron microscopic technique (SEM) performed by JSM 840A scanning microscope, JEOL, Japan.

The phase composition and crystallinity of the calcined and sintered Sr-HAp powders were determined by X-ray diffractions (XRD) (Bruker D-8 Advanced-Germany spec-

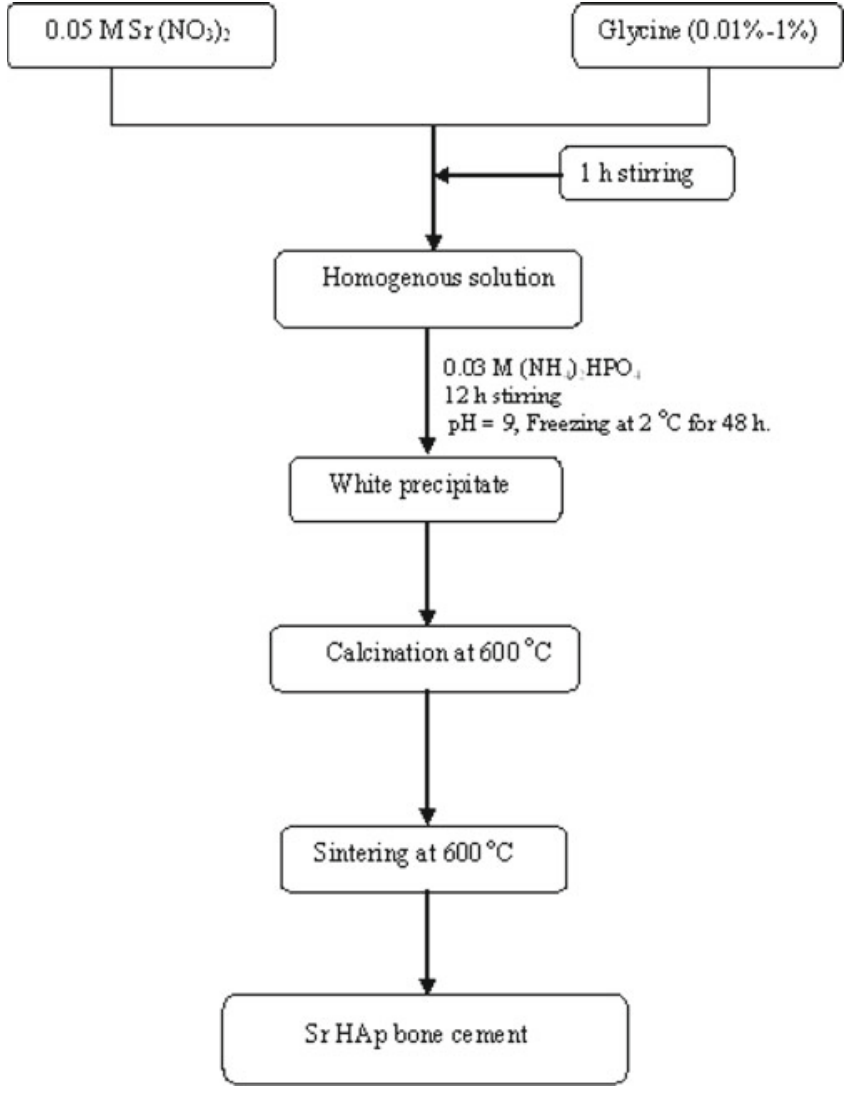

Figure 1. Schematic representation of synthesis of $\mathrm{Sr}-\mathrm{HAp}$ bone cement by soft solution freezing method.

trometer), with $\mathrm{Cu} \mathrm{K} \alpha$ radiation, $\lambda=1.5406 \AA$, generated at $35 \mathrm{kV}$ and $25 \mathrm{~mA}$. Data were collected over the $2 \theta$ range $20-60^{\circ}$ with a step size of $0 \cdot 010^{\circ}$ and a count time of $0 \cdot 2 \mathrm{~s}$. The crystallite size of the powder was calculated from the X-ray diffractions data using Scherrer's equation (Pang and Bao 2003).

$$
X_{\mathrm{S}}=0 \cdot 9 \lambda / \mathrm{FWHM} \cos \theta,
$$

where $X_{\mathrm{S}}$ is the crystallite size $(\mathrm{nm}), \lambda$ the wavelength of monochromatic X-ray beam (nm) $(\lambda=1.5406 \AA$ for $\mathrm{Cu} \mathrm{K} \alpha$ radiation), FWHM is the full width at half maximum for the diffraction peak under consideration and $\theta$ the diffraction angle $\left({ }^{\circ}\right)$.

The fraction of crystallinity, $X_{\mathrm{c}}$, of the strontium hydroxyapatite powders were determined (Degirmenbasi et al 2006) from the equation:

$$
X_{\mathrm{c}}=(0 \cdot 24 / \beta)^{3},
$$

where $\beta$ is the FWHM.

\section{Results and discussion}

FT-IR spectra of the as-synthesized powders obtained with different glycine concentrations $(0.01 \%, 0.1 \%, 0.5 \%$ and 
1 wt. \%) are shown in figure 2 . The characteristic peaks found in the spectra are attributed to strontium hydroxyapatite and no other peaks corresponding to glycine or any trace of impurities could be detected as shown in figures $2(\mathrm{a}-\mathrm{d})$. To account for them, the peaks appeared at around $1640 \mathrm{~cm}^{-1}$ and $3400 \mathrm{~cm}^{-1}$ due to the bending mode of adsorbed water, while the $\mathrm{OH}^{-}$stretching band for $\mathrm{Sr}-\mathrm{HAp}$ is shifted to higher wave numbers around $3586 \mathrm{~cm}^{-1}$ and the $\mathrm{OH}^{-}$libration band shifts from around 600 to $564 \mathrm{~cm}^{-1}$ (Fowler 1974). The IR absorption band due to phosphate groups shift to lower wave numbers for Sr-HAp (Bigi et al 2007). Apart from that the characteristic phosphate bands observed at $v_{1}$ from $962 \mathrm{~cm}^{-1}(\mathrm{Ca}-\mathrm{HA})$ to around $940 \mathrm{~cm}^{-1}(\mathrm{Sr}-\mathrm{HA})$ and $v_{4}$ from $603 \mathrm{~cm}^{-1}(\mathrm{Ca}-\mathrm{HA})$ to around $586 \mathrm{~cm}^{-1}(\mathrm{Sr}-\mathrm{HA})$ in the spectra were attributed to the phosphate $\left(\mathrm{PO}_{4}^{3-}\right)$ characteristic absorption (Bigi et al 2007; Gopi et al 2008, 2009). This change is attributed to the complete substitution of $\mathrm{Sr}^{2+}$ for $\mathrm{Ca}^{2+}$ into the lattice of apatite phase. Upon increasing the concentration of glycine, the hydroxyl stretching $(-\mathrm{OH})$ and bending modes are never lost as shown in figures 2 (ad). This is a strong indication that the formation of strontium hydroxyapatite is favoured under these concentrations. FTIR results indicated that the samples exhibit excellent purity of the as-synthesized Sr-HAp.

Figure 3 represents XRD pattern of strontium substituted hydroxyapatite obtained with different glycine concentrations. All the XRD patterns obtained for the samples are in

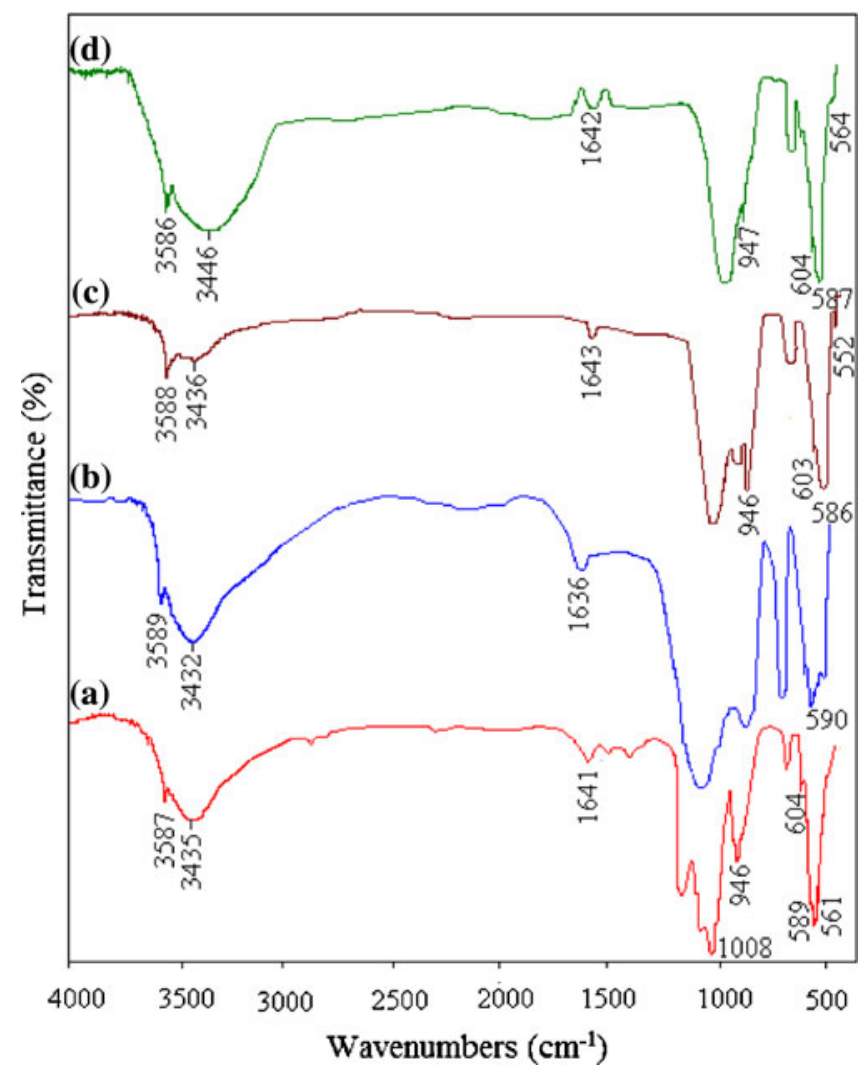

Figure 2. FT-IR spectra of Sr-HAp bone cement using various concentrations of glycine in wt.\% (a) $0 \cdot 01$, (b) $0 \cdot 1$, (c) 0.5 and (d) 1 .

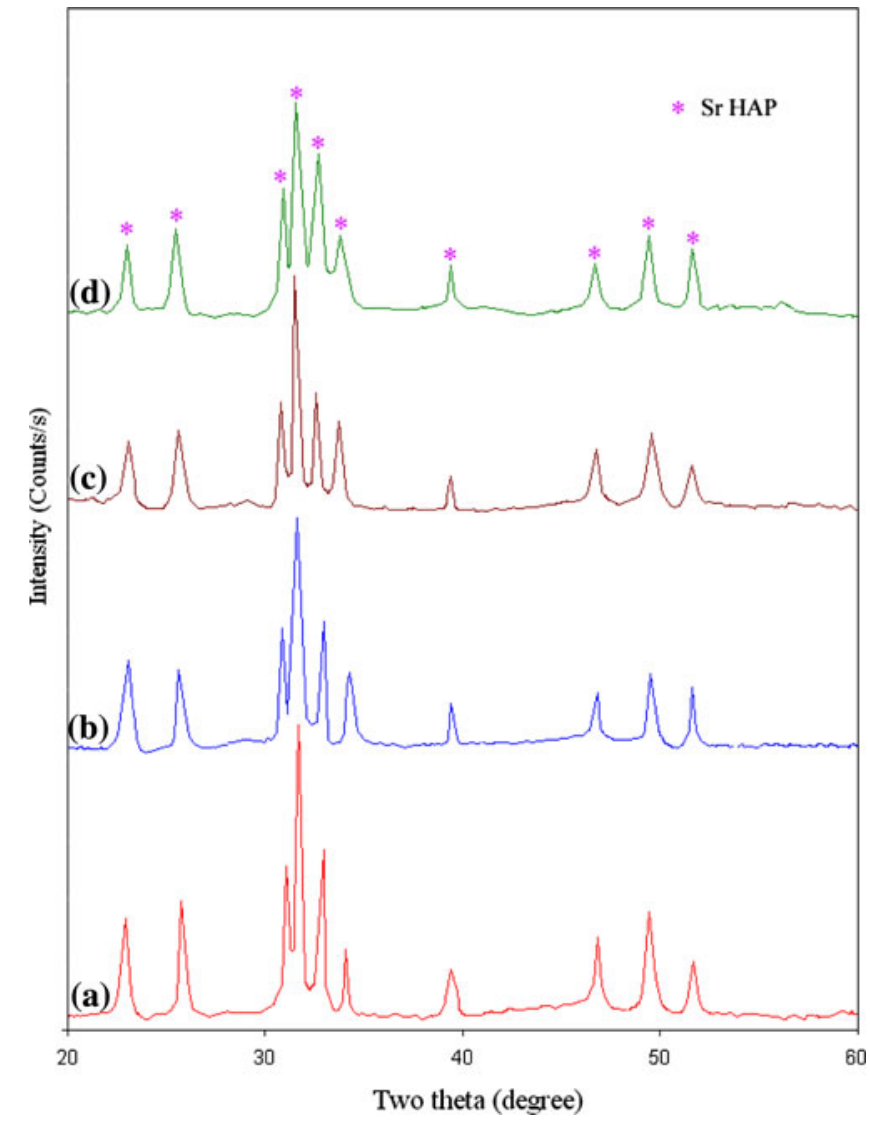

Figure 3. XRD patterns of $\mathrm{Sr}-\mathrm{HAp}$ bone cement using various concentrations of glycine in wt $\%$ (a) 0.01 , (b) $0 \cdot 1$, (c) 0.5 and (d) 1.

Table 1. Structural properties of $\mathrm{Sr}-\mathrm{HAP}$ obtained from Scherrer's equation at different concentrations of glycine in wt.\% (a) $0 \cdot 01$, (b) $0 \cdot 1$, (c) 0.5 and (d) 1 .

\begin{tabular}{lccc}
\hline Concentration $(\%)$ & Plane & FWHM & Crystallite size, $X_{\mathrm{s}}(\mathrm{nm})$ \\
\hline $0 \cdot 01$ & 002 & $0 \cdot 309$ & 24.99 \\
$0 \cdot 1$ & 002 & $0 \cdot 440$ & $17 \cdot 33$ \\
$0 \cdot 5$ & 002 & $0 \cdot 501$ & $17 \cdot 17$ \\
1 & 002 & $0 \cdot 414$ & $16 \cdot 87$ \\
\hline
\end{tabular}

good agreement with the stoichiometric strontium hydroxyapatite (JCPDS; 33-1348). All the XRD patterns obtained at different concentrations of glycine exhibit peaks belonging only to strontium hydroxyapatite, but of different intensity and sharpness. The intensity and sharpness of XRD peaks are more pronounced for the lower glycine content $(0.01 \mathrm{wt}$. \%) and tend to gradually decrease with increasing concentrations of the template. As stated above, peaks broadening accompanied by a decrease in peak height are clear symptoms of a decreasing trend in crystallinity as predicted by the Scherrer's equation (Pang and Bao 2003). This trend is confirmed by the data reported in table 1 showing that increasing added amounts of glycine resulted in smaller crystallites in the as synthesized $\mathrm{Sr}-\mathrm{HAp}$ powders. 

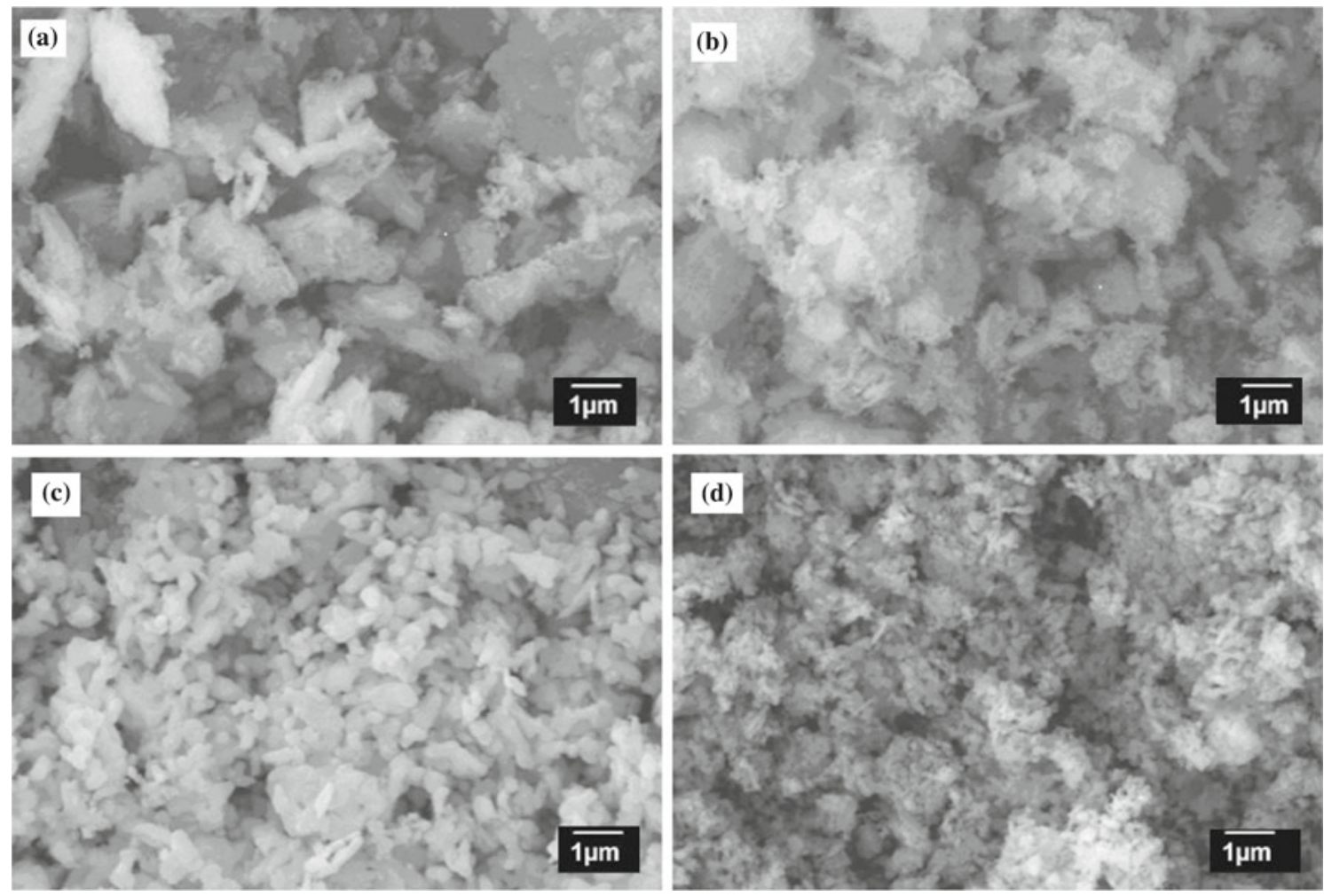

Figure 4. SEM images of Sr-HAp bone cement using various concentrations of glycine in wt\% (a) $0 \cdot 01$, (b) $0 \cdot 1$, (c) 0.5 and (d) 1 at $600{ }^{\circ} \mathrm{C}$.

SEM micrographs presented in figure 4 show the effects of addition of glycine on the morphology and microstructure of the as calcined and sintered strontium hydroxyapatite powders. The morphology of strontium hydroxyapatite powder synthesized in the presence of $0.01 \mathrm{wt} \%$ of glycine reveals a highly agglomerated strontium apatite powder (figure 4a). When the concentration of glycine was slightly increased ( $0.1 \mathrm{wt} . \%)$, the extent of agglomeration decreased in the $\mathrm{Sr}-\mathrm{HAp}$ powders (figure $4 \mathrm{~b}$ ). On further increasing the glycine concentration to $0.5 \mathrm{wt} . \%, \mathrm{Sr}-\mathrm{HAp}$ powder with well defined grain structure resulted accomplished by the significant reduction in the particle size (figure $4 \mathrm{c}$ ). This trend was even exacerbated by further doubling the concentration of glycine to $1 \mathrm{wt}$. \%. Figure $4 \mathrm{~d}$ shows that the resulting particles are smaller and appear less agglomerated. These morphological observations are consistent with the evolution of the structural parameters as a function of glycine concentration presented in table 1. From these results, it seems reasonable to hypothesize that the reactivity of the system towards precipitating the Sr-HAp powder has been decreased with increasing added amounts of glycine. Its $\mathrm{pK}$ values are 2.35 and 9.78 (http://en.wikipedia.org/wiki/Glycine), so within the $\mathrm{pH}$ range of the solutions/precipitating suspensions. The glycine species exist as anionic amine $\left(\mathrm{NH}_{2}-\mathrm{CH}_{2}-\mathrm{CO}\right)(\mathrm{Rec}-$ ommendations 1983,1984 ) having the ability to act as a chelating agent towards the $\mathrm{Sr}^{2+}$ cations and/or to absorb at the surface of the precipitated Sr-HAp particles. The chelating role is directly responsible for the reduced reactivity towards precipitating the $\mathrm{Sr}-\mathrm{HAp}$, while the adsorption at the surface of the precipitated Sr-HAp particles will enhance their colloidal stability through the repulsive interparticle forces generated. Considering that adsorption of glycine species is expected to occur from the early stage of nucleation and that the extent of adsorption should increase with increasing added amounts of glycine, this means that the growth/agglomeration rate of particles precipitated under these conditions is expected to decrease. XRD data (figure 3) and SEM observations (figure 4) concur very well with this interpretation. Hence, increasing the concentration within the $0.01-1.0 \mathrm{wt} \%$ range studied in the present work leads to smaller crystallites and particle sizes/agglomerates of the precipitated $\mathrm{Sr}-\mathrm{HAp}$ powders. This means that both kinetics of the reaction to form Sr-HAp and the kinetics of particles growth/agglomeration are expected to decrease with increasing amounts of chelating agent.

\section{Conclusions}

Strontium hydroxyapatite bone cement with high purity could be easily prepared at $2{ }^{\circ} \mathrm{C}$ by the soft solution freezing method. The formation of Sr-HAp was confirmed by FT-IR, XRD and SEM results. The addition of glycine was found to be beneficial, as it resulted in fine sized Sr-HAp 
powders. The FT-IR and XRD results have proved the formation of pure $\mathrm{Sr}-\mathrm{HAp}$ powders, while the resulting crystallites and particles/agglomerates formed became smaller with increasing added amounts of glycine as clearly evident by XRD results and SEM analysis. These effects were attributed to a chelating role of glycine soluble species towards the $\mathrm{Sr}^{2+}$ cations that slows down the reactivity towards precipitating $\mathrm{Sr}-\mathrm{HAp}$, while their adsorption at the surface of the precipitated Sr-HAp particles from the early stage of nucleation enhance their colloidal stability. The relevance of these effects increased with the increasing added amounts of glycine, explaining why the size of both the crystallites and particles/agglomerates formed became gradually smaller with increasing amounts of chelating agent. This means that the amino acid-assisted synthesis has potential application in tailoring the characteristics of $\mathrm{Sr}-\mathrm{HAp}$ bone cement.

\section{Acknowledgements}

One of the authors (DG) acknowledges the major financial support from the Indian Council of Medical Research (ICMR, IRIS ID No. 2010-08660, Ref. No. 5/20/11(Bio)/10NCD-I), Department of Science and Technology (DSTSERC, Ref. No. SR/FTP/ETA-04/2009 and DST-TSD, Ref. No. DST/TSG/NTS/2011/73), Council of Scientific and Industrial Research (CSIR, Ref. No. 01(2547/11/EMR-II, Dated 12.12.2011)) New Delhi, India and Tamilnadu State Council for Science and Technology (TNSCST), Tamilnadu in the form of major research projects. Also (LK) acknowledges the financial support from ICTP, Italy in the form of Junior Associateship. The support from CICECO, University of Aveiro, Portugal, is also acknowledged.

\section{References}

Balamurugan A, Balossier G, Torres P, Michel J and Ferreira J M F 2009 Mater. Sci. Eng. C29 1006
Bezzi G, Celotti G, Landi E, Torretta T M G L, Sopyan I and Tampieri A 2003 Mater. Chem. Phys. 78816

Bigi A, Boaniai E, Capuccini C and Gazzano M 2007 Inorg. Chim. Acta 3601009

Capuccini C et al 2008 Acta Biomater. 41885

Degirmenbasi N, Kalyon D M and Birinci E 2006 Colloids Surf. B: Biointerf. 4842

Fowler B O 1974 Inorg. Chem. 13207

Gomez-Vega J M, Saiz E, Tomsia A P, Marshall G W and Marshall S J 2000 Biomaterials 21105

Gopi D, Govindaraju K M, Prakash V C A, Kavitha L and Rajendiran N 2008 Spectrochim. Acta Part A 701243

Gopi D, Indira J, Collins Arun Prakash V and Kavitha L 2009 Spectrochim. Acta Part A $\mathbf{7 4} 282$

Guo D, Xu K, Zhao X and Han Y 2005 Biomaterials 264073 http://en.wikipedia.org/wiki/Glycine

Kalita S J and Bhatt H A 2007 Mater. Sci. Eng. C27 837

Kannan S, Neunhoefferb F G, Neubauerb J, Rebelo A H S and Ferreira J M F 2008 J. Am. Ceram. Soc. 911

Lam W M, Pan H B, Li Z Y, Yang C, Chan W K, Wong C T, Luk K D K and Lu W W 2010 Ceram. Int. 36683

Li Y, Tjandra W and Tam K C 2008 Mater. Res. Bull. 432318

Mardziah C M, Sopyan I and Ramesh S 2009 Trend Biomater. Artif. Organs $\mathbf{2 3} 105$

Ni G X, Lu W W, Xu B, Chiu K Y, Yang C, Li Z Y, Lam W M and Luk K D K 2006 Biomaterials 275127

Pan H B, Li Z Y, Lam W M, Wong J C, Darvell B W, Luk K D K and Lu W W 2009 Acta Biomater. 51678

Pang Y X and Bao X 2003 J. Eur. Ceram. Soc. 231697

Recommendations 1983, 1984 Nomenclature and symbolism for amino acids and peptides, Pure App. Chem. 56595

Sanosh K P, Chu M C, Balakrishnan A, Kim T N and Cho S J 2010 Curr. Appl. Phys. 1068

Suchanek W L, Byrappa K, Shuk P, Riman R E, Janas V F and Tenttuisen K S 2004 Biomaterials 254647

Wang H, Zhai L, Li Y and Shi T 2008 Mater. Res. Bull. 431607

Webster T J, Massa-Schlueter E L, Smith J L and Slamovich E B 2004 Biomaterials 222111

Wong K L et al 2009 Biomaterials 303810

Xue W, Moore J, Hosick H L, Bose S, Bandyopadhyay A, Lu W W, Cheung K and Luk K 2006 J. Biomed. Mater. Res. Part A 79804

Yingguang L, Zhuoru Y, Jiang C, Lianshi W and Wuhan 2008 J. Mater. Sci. Ed. 475 